\title{
Influence of Fly Ash Content and Desert Sand Replacement Ratio on the Static Elastic Modulus of Desert Sand High Strength Concrete
}

\author{
Ning LIU ${ }^{1, a}$, Tong-Tong YANG ${ }^{1, b}$, Hai-Feng LIU ${ }^{1, c^{*}}$ and Yong-Gang DU ${ }^{1, d}$ \\ ${ }^{1}$ School of Civil and Hydraulic Engineering, Ningxia University, Yinchuan, Ningxia, China \\ a1763530176@qq.com, b179975752@qq.com, cliuhaifeng1557@163.com, d1303908308@qq.com \\ ${ }^{*}$ Corresponding author
}

Keywords: High Strength Concrete, Fly Ash, Desert Sand, Static Elastic Modulus.

\begin{abstract}
In order to study the influence of fly ash content and desert sand replacement ratio on the static elastic deformation of desert sand high strength concrete, experiments on $28 \mathrm{~d}$ static compression modulus of desert sand high strength concrete with different fly ash content and desert sand replacement ratio were carried out. The regulation on the influence of fly a sh content and desert sand replacement ratio on $28 \mathrm{~d}$ static compression modulus of desert sand high strength concrete was analyzed. Experimental results showed that with the increase of desert sand replacement ratio, 28d static elastic modulus of desert sand high strength concrete increased firstly, then declined. With the enhancement of fly ash content, 28d static elastic modulus of desert sand high strength concrete declined.
\end{abstract}

\section{Introduction}

Fly ash is waster discharged from thermal power plant, which was used as supplement to improve the workability, durability and anti-carbonization ability of concrete [1-2]. China is one of the most serious desertification countries, especially in the northwest region. With the implementation of the "The Belt and Road" strategy, large-scale infrastructures were carried out, which intensified the contradiction between supply and demand of natural sand in these desertification regions. It is necessary to make desert sand concrete suitable for engineering application, which is beneficial to sustainable development in these regions.

At present, scholars at home and abroad had done lots of researches on the mechanical properties of desert sand concrete [3-11]. However, there are few documents on the influence of fly ash content and desert sand replacement ratio on the static elastic modulus of desert sand high strength concrete. In this article, the $28 \mathrm{~d}$ static compression modulus experiments of desert sand high strength concrete with various fly ash content and desert sand replacement ratio were carried out. The influence of fly ash content and desert sand replacement ratio on the static elastic modulus of desert sand high strength concrete was analyzed, which can provide guidance and reference for the engineering application of the desert sand.

\section{Experimental Materials}

The following ingredients were adopted for desert sand high strength concrete. Locally produced ordinary Portland branded as Saima in Ningxia was used. Artificial crushed coarse aggregate was bought from Zhenbeipu town of Ningxia, the particle diameter of which was from $5 \mathrm{~mm}$ to $20 \mathrm{~mm}$. Medium sand was local washed river sand, the fineness modulus of which was 2.95. Desert sand was obtained from the Maowusu desert in Yanchi county of Ningxia, the clay content, void ratio and fineness modulus of which were $0.14 \%, 40.95 \%$ and 0.194 , respectively. Grade I fly ash made from Ningxia power plant was adopted, the water content and loss on ignition of which were $0.2 \%$ and $2.8 \%$. High performance water reducing agent produced by Beijing Mu Lake was adopted. Water was tap water. 


\section{Experimental Program}

The mix ratio of desert sand high strength concrete was as following [10]. W/C ratio, the usage of water and sand ratio were $0.24,180 \mathrm{~kg} / \mathrm{m}^{3}$ and $30 \%$, respectively. The content of water reducing agent is $0.4 \%$ that of cementing material. There were three level of fly ash content, which was $0 \%$, $15 \%, 25 \%$. Under the same amount of fly ash content, desert sand replacement ratio was $0 \%, 20 \%$, $30 \%, 40 \%, 60 \%, 80 \%$ and $100 \%$, respectively.

Concrete specimen was cast in moulds with the dimension of $150 \times 150 \times 300 \mathrm{~mm}$. All specimens were demoulded after $24 \mathrm{~h}$, then cured in standard curing room for $28 \mathrm{~d}$. According to Ref.[12], the static elastic modulus of desert sand high strength concrete was tested by elastic modulus measuring instrument. Each group was prepared with six specimens, three of which was for measuring the axial compressive strength, three for measuring the static elastic modulus.

\section{Experimental Results and Analysis}

The static elastic modulus is calculated by the following formula [12].

$$
E_{c}=\frac{\left(P_{a}-P_{0}\right)}{A} \cdot \frac{L}{\Delta N}
$$

where $P_{o}$ is the load when the stress at the intersecting surface of specimens reaches $0.5 \mathrm{MPa} . A$ is the area of the intersecting surface of specimens. $P_{a}$ is the load when the stress at the intersecting surface of the specimens reaches the axial compressive strength. $L$ is gauge length which is equal to $150 \mathrm{~mm} . \Delta N$ is the deformation difference measured by two amesdials when the axial compressive force $P_{o}$ and $P_{a}$ acts on the specimen. The experimental results were shown in Tab. 1.

Tab. 1 Experimental result of static elastic modulus

\begin{tabular}{cccccc}
\hline Group & $\begin{array}{c}\text { Static elastic } \\
\text { modulus[GPa] }\end{array}$ & Group & $\begin{array}{c}\text { Static elastic } \\
\text { modulus[GPa] }\end{array}$ & Group & $\begin{array}{c}\text { Static elastic } \\
\text { modulus[GPa] }\end{array}$ \\
\hline T001 & 40.14 & T151 & 39.27 & T251 & 38.00 \\
T002 & 44.20 & T152 & 41.60 & T252 & 39.26 \\
T003 & 44.00 & T153 & 40.62 & T253 & 37.59 \\
T004 & 41.85 & T154 & 39.90 & T254 & 37.40 \\
T005 & 38.79 & T155 & 38.60 & T255 & 35.59 \\
T006 & 38.30 & T156 & 38.00 & T256 & 35.00 \\
T007 & 37.99 & T157 & 37.30 & T257 & 33.70 \\
\hline
\end{tabular}

Note: Symbol $i j$ of $T_{i j k}$ represents fly ash content, in which $i j=00,15,25$ respectively represents fly ash content of $0 \%, 15 \%, 25 \%$. $K$ represents desert sand replacement ratio, in which $K=1,2,3,4,5$, 6,7 respectively represents desert sand replacement ratio of $0 \%, 20 \%, 30 \%, 40 \%, 60 \%, 80 \%$ and $100 \%$.

\section{Influence of Desert Sand Replacement Ratio on the Static Elastic Modulus of Desert Sand High Strength Concrete}

Fig.1 showed the relation between desert sand replacement ratio and static elastic modulus. As shown in Fig.1 and tab.1, when fly ash content was equal to 0\%, compared with the static elastic modulus of high strength concrete with the desert sand replacement ratio of $0 \%$, the static elastic modulus of desert sand high strength concrete with the desert sand replacement ratio of $20 \%, 30 \%$, $40 \%, 60 \%, 80 \%$ and $100 \%$ increased respectively $10.1 \%, 9.6 \%, 4.3 \%,-3.4 \%,-4.6 \%$ and $-5.4 \%$. When fly ash content was equal to $15 \%$, compared with the static elastic modulus of high strength concrete with the desert sand replacement ratio of $0 \%$, the static elastic modulus of desert sand high strength concrete with the desert sand replacement ratio of $20 \%, 30 \%, 40 \%, 60 \%, 80 \%$ and $100 \%$ increased respectively $5.9 \%, 3.4 \%, 1.6 \%,-1.7 \%,-3.2 \%$ and $-5.0 \%$. When fly ash content was equal 
to $25 \%$, compared with the static elastic modulus of high strength concrete with desert sand replacement ratio of $0 \%$, the static elastic modulus of desert sand high strength concrete with the desert sand replacement ratio of $20 \%, 30 \%, 40 \%, 60 \%, 80 \%$ and $100 \%$ increased respectively $3.3 \%$, $-1.1 \%,-1.6 \%,-6.3 \%,-7.9 \%$ and $-11.3 \%$. Thus, it can be concluded that with the increase of the desert sand replacement ratio, the static elastic modulus of desert sand high strength concrete increased firstly, then declined. When the desert sand replacement ratio was equal to $20 \%$, the static elastic modulus can reached the maximum value.

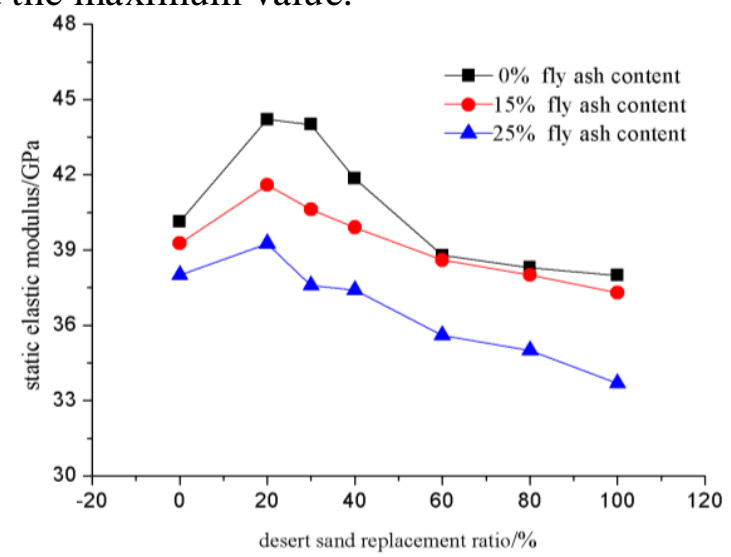

Fig. 1 Relation between desert sand replacement ratio and static elastic modulus

\section{Influence of Fly Ash Content on the Static Elastic Modulus of Desert Sand High Strength Concrete}

Fig. 2 showed the relation between fly ash content and static elastic modulus of desert sand high strength concrete. As shown in Fig.2 and tab.1, when desert sand replacement ratio was equal to 0\%, compared with the static elastic modulus of high strength concrete with the fly ash content of $0 \%$, the static elastic modulus of desert sand high strength concrete with the fly ash content of $15 \%$ and $25 \%$ increased respectively $-2.2 \%$ and $-5.3 \%$. When desert sand replacement ratio was equal to $20 \%$, compared with the static elastic modulus of high strength concrete with the fly ash content of $0 \%$, the static elastic modulus of desert sand high strength concrete with the fly ash content of $15 \%$ and $25 \%$ increased respectively $-5.9 \%$ and $-11.2 \%$. When desert sand replacement ratio was equal to $30 \%$, compared with the static elastic modulus of high strength concrete with the fly ash content of $0 \%$, the static elastic modulus of desert sand high strength concrete with the fly ash content of $15 \%$ and $25 \%$ increased respectively $-7.7 \%$ and $-14.6 \%$. When desert sand replacement ratio was equal to $40 \%$, compared with the static elastic modulus of high strength concrete with the fly ash content of $0 \%$, the static elastic modulus of desert sand high strength concrete with the fly ash content of $15 \%$ and $25 \%$ increased respectively $-4.7 \%$ and $-10.6 \%$. When desert sand replacement ratio was equal to $60 \%$, compared with the static elastic modulus of high strength concrete with the fly ash content of $0 \%$, the static elastic modulus of desert sand high strength concrete with the fly ash content of $15 \%$ and $25 \%$ increased respectively $-0.5 \%$ and $-8.2 \%$. When desert sand replacement ratio was equal to $80 \%$, compared with the static elastic modulus of high strength concrete with the fly ash content of $0 \%$, the static elastic modulus of desert sand high strength concrete with the fly ash content of $15 \%$ and $25 \%$ increased respectively $-0.8 \%$ and $-8.6 \%$. When desert sand replacement ratio was equal to $100 \%$, compared with the static elastic modulus of high strength concrete with the fly ash content of $0 \%$, the static elastic modulus of desert sand high strength concrete with the fly ash content of $15 \%$ and $25 \%$ increased respectively $-1.8 \%$ and $-11.3 \%$. Thus, with the enhancement of fly ash content, the static elastic modulus of the desert sand high strength concrete declined gradually. 


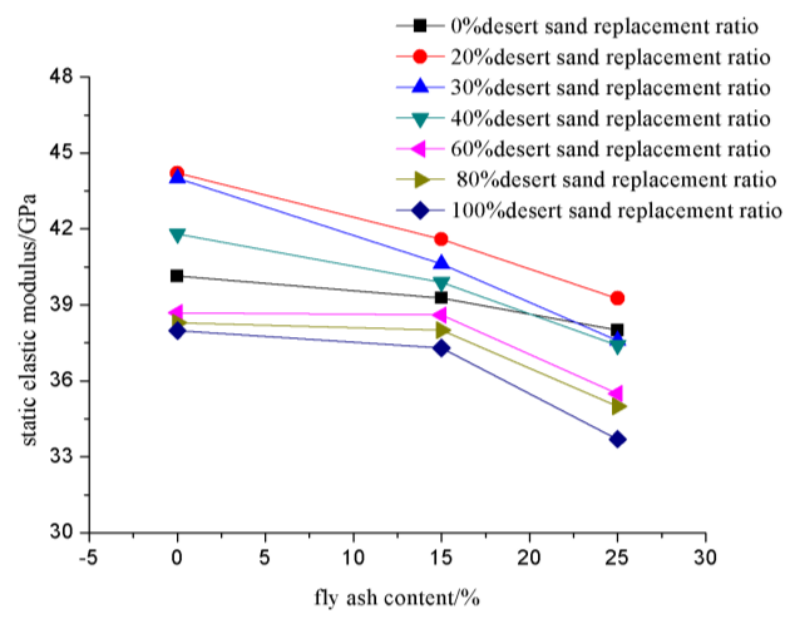

Fig. 2 Relation between fly ash content and static elastic modulus

\section{Conclusions}

In this article, experiments on $28 \mathrm{~d}$ static compression modulus of desert sand high strength concrete with different fly ash content and desert sand replacement ratio were carried out. The regulation on the influence of fly ash content and desert sand replacement ratio on $28 \mathrm{~d}$ static compression modulus of desert sand high strength concrete was analyzed. Experimental results showed that with the increase of desert sand replacement ratio, the static elastic modulus of the desert sand high strength concrete increased firstly, then declined. When desert sand replacement ratio was equal to $20 \%$, the static elastic modulus can reach the maximum value. With the enhancement of fly ash content, the static elastic modulus of desert sand high strength concrete declined gradually, which can provide guidance and reference for the application of desert sand in engineering.

\section{Acknowledgments}

The support of National Natural Science Foundation of China (No. 51368048 and 11162015) and National University Innovation Research and Training Program (201510749012 and G201610749024) are gratefully acknowledged.

\section{References}

[1] Lu L H, Pan G H, Chen S L, et al. Strength of concrete with different contents of fly ash. Journal of Shenyang University of Technology. 1(2009): 107-111.

[2] Wang X, Wang Y B,Yang L S, et al. High-performance high-volume fly ash concrete. Bulletin of the Chinese Ceramic Society. 3(2013): 523-527.

[3] Ma J R, Liu H F, Yang W W. Study on the mechanical behaviors of desert sand concrete from Muus desert. Science Technology and engineering. 15(2015): 267-272.

[4] Yang W W, Chen Y L, Liu H F, et al. Research on the mechanical properties of desert sand high strength concrete. Concrete. 11(2014):100-102.

[5] Liu J H, Jin D M, Bao W Z, et al. Research on the mechanical properties of desert sand concrete. China Concrete. 9(2013): 66-6.

[6] Song J X, Wang C B, Wang D P, et al. The determination of Maowusu fine sand concrete intensity formula. Ningxia Engineering Technology.1(2010):16-18. 
[7] Chen Y L, Ma J R, Liu H F, et al. Influence of fly ash and desert sand content on the compressive strength of high strength concrete. Concrete. 7(2014): 80-84.

[8] Zhang G X, Song J X, Yang J S, et al. Performance of mortar and concrete made with a fine aggregate of desert sand. Building and Environment. 41(2006): 1478-148.

[9] Zhang G X, Song J X, Yang W W,et al. Effects of different desert sand on properties of cement mortar and concrete. Journal of Ningxia University (Natural Science Edition). 24(2003): 63-65.

[10]Fu J, Yang D, Liu H F, et al. Influence of fly ash dosage and desert sand replacement ratio on the mechanical properties of high strength desert sand concrete. Science Technology and engineering. 15(2015): 238-242.

[11]Fu J, Ma J R, Liu H F. Influence of fly ash dosage and desert sand replacement ratio on the mechanical properties of desert sand concrete. Journal of Guangxi University: Nat Sci Ed. 40(2015):93-98.

[12]China Academy of Building Research. GB/T 50081-2002, Standard for test method of mechanical properties on ordinary concrete. Beijing: China Architecture and Building Press, 2002. 